Int. J. Dev. Biol. 56: 377-383 (2012)

doi: $10.1387 / \mathrm{ijdb} .113416 \mathrm{bu}$

\title{
Expression of Sox family genes in early lamprey development
}

\author{
BENJAMIN R. UY, MARCOS SIMOES-COSTA, TATJANA SAUKA-SPENGLER and MARIANNE E. BRONNER* \\ Division of Biology, California Institute of Technology, Pasadena, CA, USA
}

\begin{abstract}
Members of the Sox (Sry-related high mobility group box) family of transcription factors play a variety of roles during development of both vertebrates and invertebrates. A marked expansion in gene number occurred during the emergence of vertebrates, apparently via gene duplication events that are thought to have facilitated new functions. By screening a macroarrayed library as well as the lamprey genome, we have isolated genes of the Sox B, D, E and F subfamilies in the basal jawless vertebrate, lamprey. The expression patterns of all identified Sox genes were examined from gastrulation through early organogenesis (embryonic day 4-14), with particular emphasis on the neural crest, a vertebrate innovation. Coupled with phylogenetic analysis of these Sox genes, the results provide insight into gene duplication and divergence in paralog deployment occurring during early vertebrate evolution.
\end{abstract}

KEY WORDS: Sox gene, lamprey, cyclostome, neural crest

Many transcription factors of the Sox gene family are critical for a number of developmental processes, most notably sex determination, neural crest development and neurogenesis (Laudet et al., 1993; Hong et al., 2005; Betancur et al., 2010). This family is comprised of more than 30 genes that have been classified into eight paralogy groups [SoxA-SoxH; (Schepers et al., 2002)]. Sox genes are characterized by the presence of a single High Mobility Group box (HMG box), a 79 amino acid DNA binding domain that has affinity to the WWCAAW motif (Laudet et al., 1993). These factors are generally expressed in a dynamic, tissue specific manner, and often interact with other transcription factors (Prior et al., 1996).

Members of the Sox gene family are found across the animal kingdom, and it has been suggested that the major Sox groups (i.e. B, C, D and E) were already present in the common bilaterian ancestor, whereas group A genes are specific to mammals (Jager et al., 2006). Expansion in the number of vertebrate Sox genes is thought to be due to major gene duplication events, initially occurring during early stages of metazoan evolution and later during the transition between non-vertebrate chordates and vertebrates (Prior et al., 1996; Dehal et al., 2005). Gnathostomes (jawed vertebrates) have undergone two rounds of whole genome duplications (Escriva et al., 2002), whereas estimates for the number of rounds of duplication in agnathans like lamprey range from one to two. It is not yet clear whether supernumerary copies of lamprey genes arose via whole genome-wide duplication, or via independent duplication events (Tomsa et al., 1999; McCauley et al., 2006; Neidert et al., 2001; Zhong et al., 2011).

Classification of Sox genes was first done by Wright et al., 1993, using partial sequences from mouse SOX genes. This study defined the six paralogous groups (A-F) which are the basis of the current classification (Wright et al., 1993). Four more groups were subsequently added to include recently identified paralogs (Bowles et al., 2000). Nevertheless, members of the same groups do not always have similar roles or expression patterns, indicating that recent paralogs can adopt new functions with relative ease (Bowles et al., 2000).

In the neural crest, a vertebrate innovation that contributes to the peripheral nervous system and craniofacial skeleton, the function of Sox genes has been studied at many stages. For example, gnathostome SoxE family members (Sox8, Sox9, and Sox10) are expressed in premigratory neural crest progenitors, migrating neural crest cells, as well as at later stages, in numerous neural crest derivatives (Sauka-Spengler et al., 2008), similar to their lamprey paralogs (McCaulsey et al., 2006). SoxD family members (Sox5 and Sox6) are found in cranial ganglia (Morales et al., 2007) and

Abbreviations used in this paper: HMG, high mobility group; Sox, Sry-related high mobility group box.

\footnotetext{
*Address correspondence to: Marianne E. Bronner. Division of Biology 139-74, California Institute of Technology, Pasadena, CA 91125 USA.

Tel: +1-626-395-3355. e-mail: mbronner@caltech.edu
}

Supplementary Material (one figure) for this paper is available at: http://dx.doi.org/10.1387/ijdb.113416bu

Accepted: 13 February 2012. Final, author-corrected PDF published online: 15 June 2012.

ISSN: Online 1696-3547, Print 0214-6282

(C) 2012 UBC Press

Printed in Spain 
cartilage elements of neural crest origin. Additionally, gnathostome SoxB family members have been shown to play an essential role in differentiation of late neural crest derivatives (Wakamatsu et al., 2004).

Given the important function of Sox genes in gnathostomes, we sought to identify and characterize novel lamprey genes of the SoxD and SoxF subfamilies, as well as additional members of the SoxB and SoxE groups. As one of the basal-most extant vertebrates, analysis of the deployment of paralogous genes in lamprey offers the opportunity to examine events in early emergence of vertebrate specific features. Comparative amino acid analysis between lamprey and other vertebrate Sox genes provides insight into the evolutionary history of early vertebrates, as well as duplication events occurring early in the vertebrate lineage.

\section{Results and Discussion}

\section{Phylogenetic analysis}

The screening of a full-length cDNA library (Sauka-Spengler et al., 2007) coupled with BLAST searches of the lamprey genome, allowed identification of four new lamprey Sox orthologs, from Sox families B, DE and F. We also included in our analysis the three SoxE orthologs previously described in McCauley et al., 2006.

Three SoxB genes were identified in this study - SoxB1b, SoxB2 and a putative SoxB1a gene. The lamprey SoxB2 groups

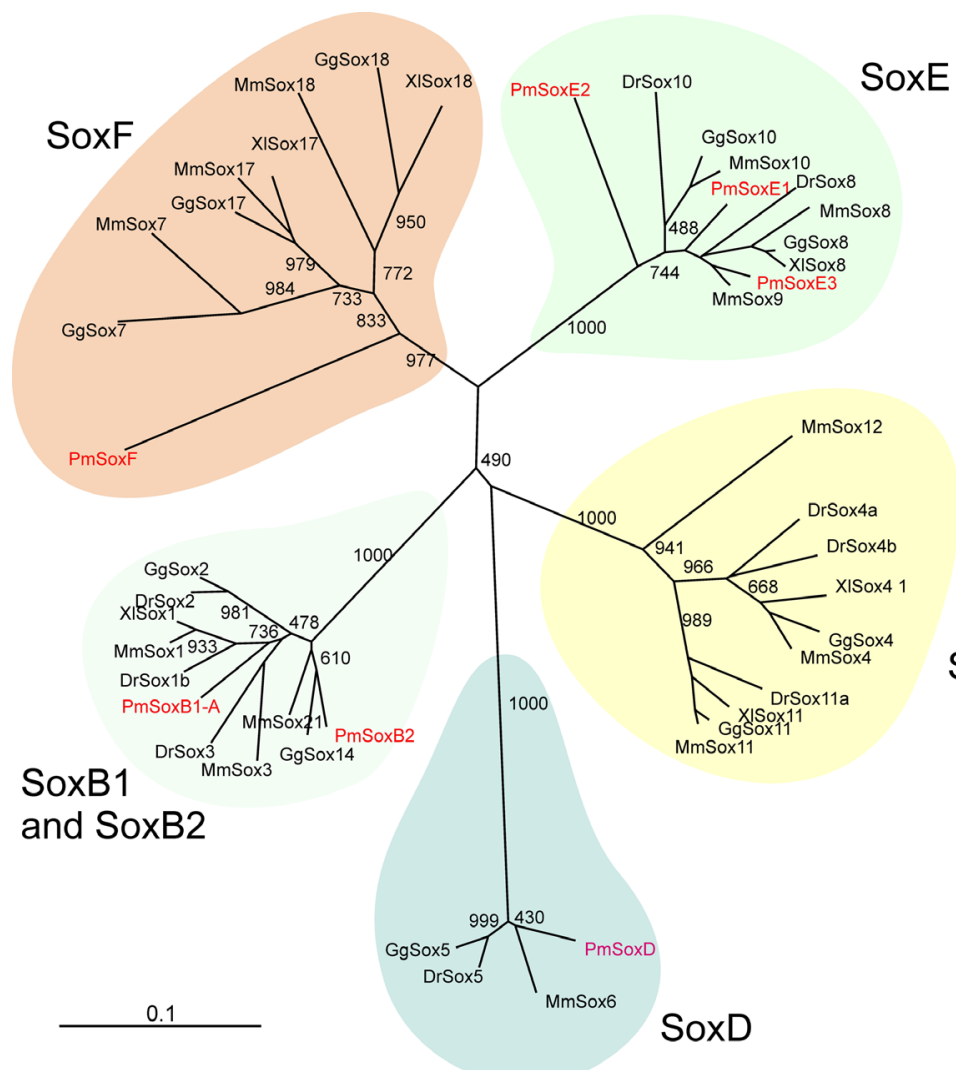

Fig. 1. Phylogenetic analysis of lamprey Sox genes. Unrooted phylogenetic tree of Sox genes obtained from a neighbor joining analysis performed on ClustalX. The HMG box protein sequences were used in the construction of the tree. Boxes highlight the families of Sox genes. Abbreviations: Dr, Danio rerio; Gg, Gallus gallus; Mm, Mus musculus; Pm, Petromyzon marinus; $\mathrm{Xl}$, Xenopus laevis. with the gnathostome SoxB2 subfamily (Sox14, 21) in our phylogenetic analysis, while SoxB1-A clusters with the Sox1/2/3 paralogy group. The presence of orthologs of SoxB1 and SoxB2 in the lamprey is expected since the duplication that gave rise to these genes is thought to be ancient having occurred before the deuterostome/protostome split (Mckimmie et al., 2005; Zhong et al., 2011). The putative SoxB1a gene we have cloned seems to be an ortholog of the Sox2 gene due to the similarity of the 5' fragment of the transcript. This gene lacks a HMG box, which precludes a more detailed analysis of its phylogenetic position. However, the expression data obtained for this gene (see below) suggests that it is likely related to the other SoxB genes analyzed.

We identified only a single SoxD family in lamprey that is apparently quite divergent from the other vertebrate SoxDs and more similar to Sox6 group. However, this may be an artifact due to the large number of amino acid substitutions observed in this ortholog (Fig. 1, S1). The lamprey SoxF, on the other hand, clusters to the base of the Sox7/18/17 branch. Thus, our data suggest that there is one lamprey ortholog for half of the major Sox families (D, F, B2), consistent with the possibility that the duplication events that led to the expansion of paralogs in such families took place after the Cyclostome/Gnathostome split.

\section{Expression pattern of SoxB family members}

The SoxB family is known to play a major role in neural induction and differentiation. In zebrafish, SoxBs are expressed at an early stage starting at the anterior neural plate and throughout the CNS (Rauch et al., 2003; Thisse et al., 2005). Whole mount in situ hybridization of the SoxB family revealed that SoxB1a, SoxB1b, and SoxB2 are all expressed in the neural plate at embryonic day (E) 4, (Fig. 2A,B,C). Similarly at E5, SoxB1a and SoxB1b have expression patterns in the neural tube with the exception of its anterior-dorsal aspect (Fig. 2 A,B), whereas SoxB2 is expressed continuously throughout the dorsal neural tube (Fig. 2C). At E6.5, by which time neural crest cells are within the dorsal aspect of the neural tube preparing to emigrate, SoxB1a and SoxB2 are expressed on the dorsal aspect of the neural tube (Fig. 2A,C) while SoxB1b is absent from the anterior-dorsal region (Fig. 2B). At E8, SoxB genes are expressed in the neural tube as well as in the forming branchial arches. Analysis of sectioned embryos reveals that SoxB2 is expressed mainly in the neural tube, the cranial ganglia, trigeminal ganglia, and in cardiac tissue.

Finally between E10-E14, the SoxBs are expressed in the neural tube and in the brachial arches. At E14, SoxB1a and SoxB1b are expressed in the branchial arches. Similarly SoxB2 is expressed in both neural tissue and mesoderm-derived portions of the branchial arches. SoxB2 is also expressed in cardiac and other non-neural crest derived tissue. These data suggest that the SoxB genes are expressed in similar domains but in a distinct temporal sequence, first with SoxB2, followed by SoxB1a and then SoxB1b. Despite their staggered temporal expression, all SoxBs are present in migrating neural crest cells as well as neural crest derivatives such as cranial ganglia and branchial arches. SoxB2 is present in both premigratory and migrating neural crest cells. 


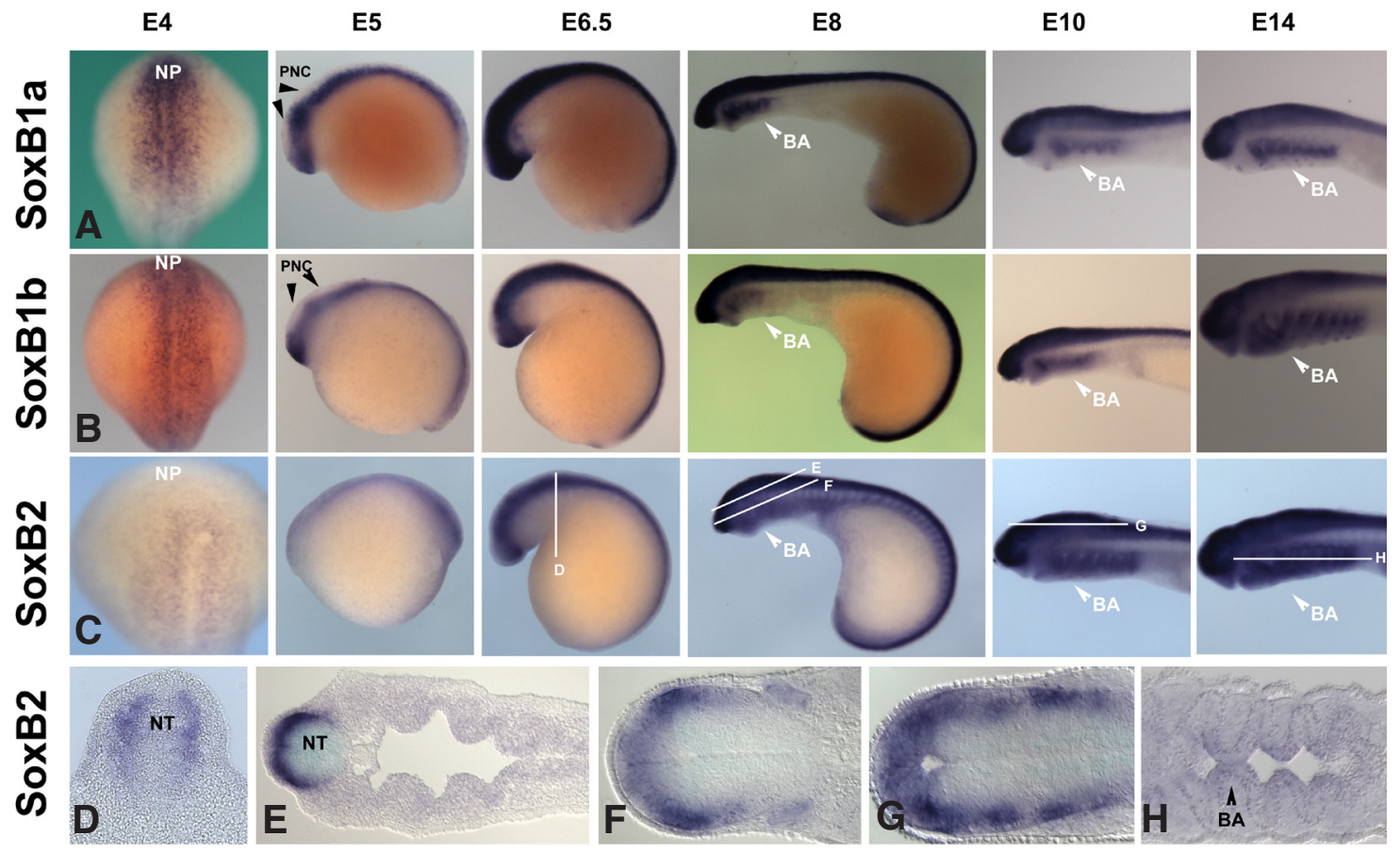

Fig. 2. The SoxB genes are expressed within the neural plate, neural tube and branchial arches. SoxB1a, 4-14 days: (A) SoxB1a is not expressed in pre-migratory neural crest at E5, with expression initiating at E6 at the onset of neural crestemigration. SoxB1b, 4-14 days: (B) SoxB1bis notexpressed at $E 5$ or E6 in pre-migratory neural crest. SoxB2, 4-14 days: (C) and sections (D-H) from 6.5 day, 8 day, 10 day, and 14 day, is expressed throughout the neural tube atE5and E6. Sections reveal SoxB2's presence at later stages in the neural tube, cranial ganglia, and ectoderm derived portions of the branchial arches. NP, neural plate; PNC, pre-migratory neural crest; NT, neural tube; $B A$, branchial arch.
In Xenopus, SoxBs play a role in neural plate formation and also have later roles throughout CNS formation (Cunningham et al., 2008; Kishi et al., 2000, Rodgers et al., 2008). In chick, SoxBs are also expressed in the neural plate and along the neural tube. In Mice, SoxBs are all expressed in the primitive streak ectoderm. Sox 1 is expressed early on in the neural folds. Sox 2 and 3 are found in the forming neural plate onward (Wood et al., 1999).

\section{Expression pattern of SoxD family members}

SoxDs are expressed widely in vertebrate neural tissues, forebrain, fast muscles, somites, mytome, and cardiac precursors (Wang et al., 2011; Von Hofsten et al., 2008; Kudoh et al.,
2001). SoxDs are necessary for formation of the notochord and chondrogenesis. They are also found in glial cells and other early NC lineages (Smits \& Lefebvre, 2003; Lefebvre et al., 1998; PerezAlcala et al., 2004). In lamprey, SoxD is expressed at high levels on the neural plate border and along the neural folds at E4 (Fig. $3 A)$. At later stages, SoxD is not expressed in the premigratory crest but is expressed along the neural tube (Fig. 3B). At E8, it is observed in the optic vesicle (Fig. 3 D, D'). Beginning at E10, SoxD is expressed in the endoderm- and mesoderm-derived portions of the branchial arches (Fig. 3 E,E',E”). From E12-E16, the mesenchymal portions of the branchial arches condense to form the branchial cartilage (Fig. $3 \mathrm{~F}-\mathrm{H}, \mathrm{F}{ }^{\prime}-\mathrm{H}^{\prime}$ ). Interestingly, at

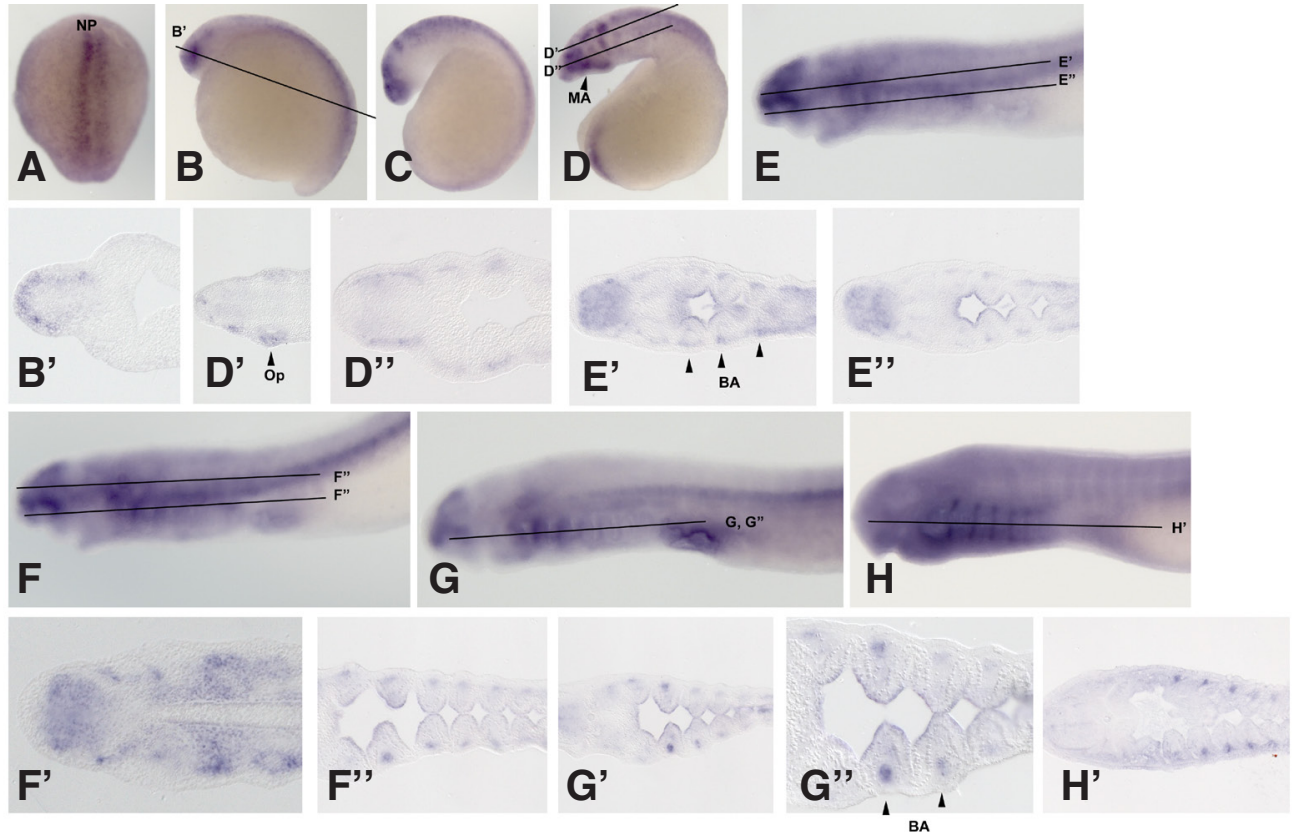

Fig. 3. SoxD expression. SoxD is expressed from 4 - 16 day (A$\mathbf{H})$, sections $\left(\mathbf{B}^{\prime}-\mathbf{H}^{\prime}\right)$ beginning on the neural plate border (A) and progressing to various neural crest derivatives, optic vesicle (D, $\left.\mathbf{D}^{\prime}\right)$, branchial arches (E,E',E"), and branchial arch cartilage (F-H \& $\left.\mathbf{F}^{\prime \prime}-\mathbf{H}^{\prime}\right)$. Beginning E8 (D) SoxD is expressed in forming branchial arch progenitors, optic vesicle and mandibular arch. From E10-E16 (E-H), expression in the forebrain and heart are decreased over time while expression of SoxD is consistent with branchial arch cartilage condensation. Np: neural plate, Op: optic vesicle, BA: branchial arch. MA: mandibular arch 


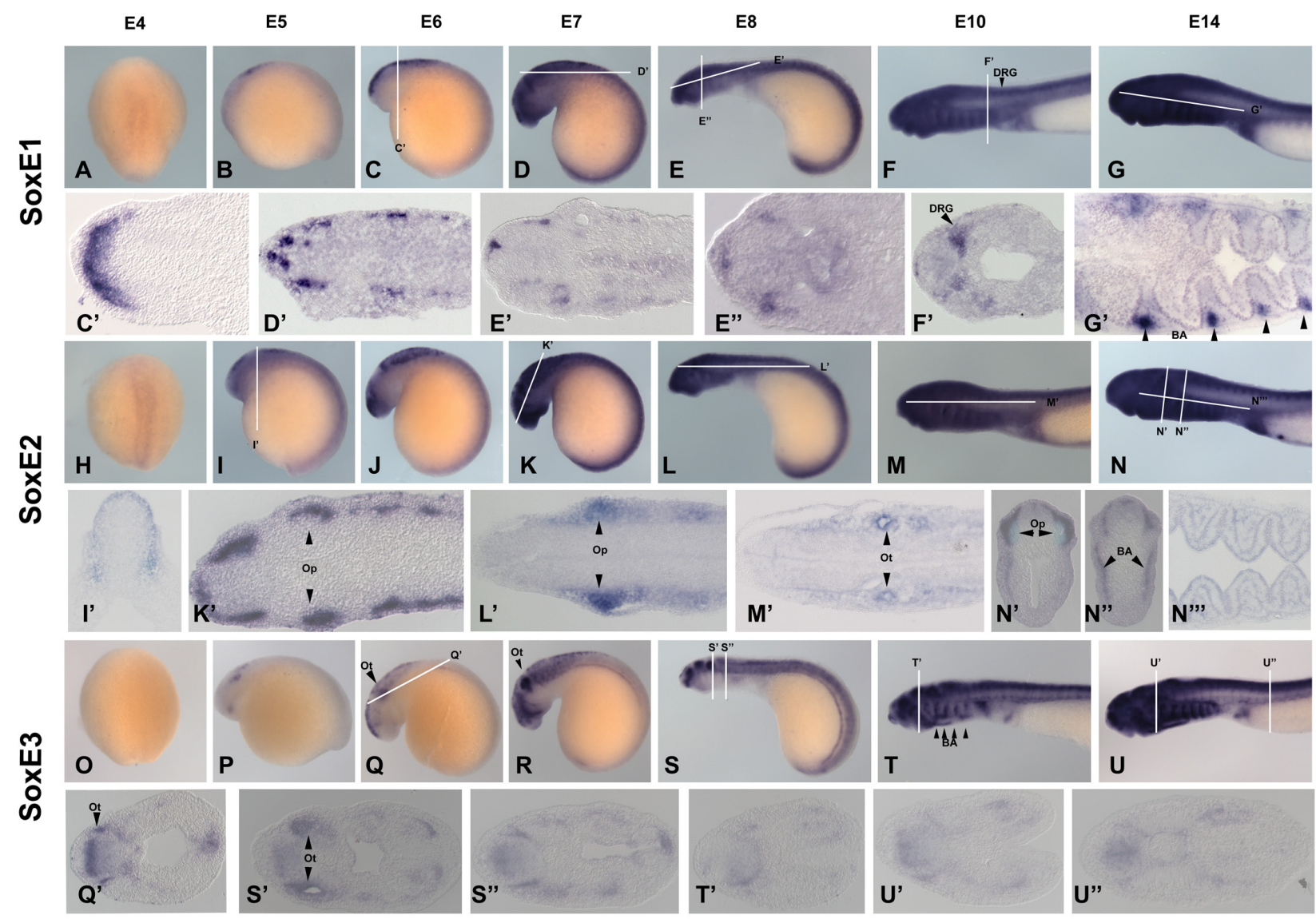

Fig. 4. SoxE Expression. The SoxE family show low level of early expression with SoxE1 and E2 expression in the neural plate at E4 (A,H). SoxE1 (A-

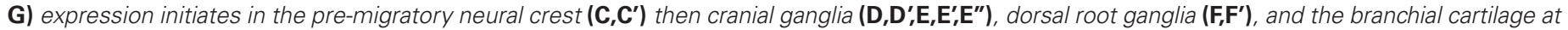

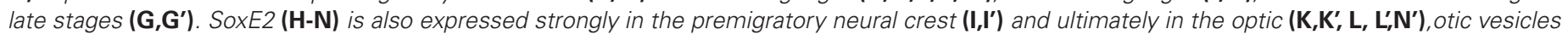

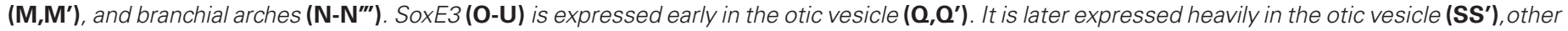
crancial ganglia (S-U), neural tube, branchial arches (S-U). Op: optic vesicle, Ot: otic vesicle, BA: branchial arch.

E14, SoxD is heavily expressed in the heart but not at prior or subsequent stages.

\section{Expression pattern of SoxE family members}

The SoxE family has three subgroups denoted SoxE1, E2, and E3 (McCauley and Bronner-Fraser, 2006). At E4, SoxE1 and SoxE2 both display low levels of expression in the neural plate (Fig. $4 \mathrm{~A}, \mathrm{H}$ ) whereas SoxE3 is not yet expressed (Fig. 4O). By E5, all SoxEs exhibit expression in the neural tube as well as distinct domains in the embryo. At E5-E7, SoxE1 is observed in two regions of the anterior-dorsal aspect of the neural tube (Fig. 4 B-D). At later stages, it is expressed in the neural tube, cranial ganglia (Fig. 4 D,D') dorsal root ganglia (Fig. 4 F,F') and in mesoderm and neural crest derived portions of the branchial arches cartilage (Fig $4 \mathrm{G}$ ,G'). SoxE2 is expressed similarly but with higher intensity (Fig. $4 \mathrm{I}-\mathrm{K})$. At older stages, SoxE2 is expressed in the neural tube, cranial ganglia (Fig. 4 K-K'), optic (Fig. 4 L,L') and otic vesicles (Fig. 4 M,M'), and branchial arches (Fig. $4 \mathrm{~N}-\mathrm{N}$ '”). SoxE3 exhibits a strong signal starting at E5 in the optic vesicle (Fig. 4P). It is strongly expressed during neural crest migration. From E6-E14, SoxE3 is very prominently expressed in the otic vesicles (Fig. 4 Q-S,S'), cranial ganglia (Fig . 4S), neural tube, and branchial arches (Fig. 4 S-U,S"-U”).

\section{Expression pattern of SoxF family member}

In vertebrates, SoxFs are involved with vascular development and cardiogenesis. They are expressed in structures such as the aortic arch, circulatory system, and pharyngeal arches in addition to parts of the CNS (Zhang et al., 2005; Kyuno et al., 2008). We isolated a single SoxF gene. At gastrula stages, SoxF is expressed in involuting cells in the dorsal lip of the blastopore (Fig. 5 A,B). At the neurula stage (E4.5), SoxF is found in the neural plate (Fig. 5C). Expression in precursor cells to the thyroid gland begins at $E 7$, whereas by E8, SoxF is observed in tissues surrounding the notochord (Fig. 5D,E,L). Low levels of SoxF are observed in cardiac precursors at E10 (Fig. 5I). At E12, SoxF is strongly expressed in the anterior branchial arches, similar to that noted for SoxD (Fig. 5J).

\section{Conclusion}

Taken collectively, our phylogenetic and expression data provide interesting insights into the evolution of Sox genes in vertebrates. Surprisingly, we were only able to find one ortholog for half of the major Sox families (D, F, B2). This suggests that either these families expanded after emergence of jawed vertebrates, or that there was extensive loss of these Sox genes in lamprey. For the remaining families, the Sox genes appear to have undergone 
independent duplications though there may be some bias toward particular paralogs. For example, SoxE1 is most similar to Sox9 and SoxE2 to Sox8. Based on the positions of various genes, we speculate that the SoxB2 gene (Sox14) and SoxD genes either diverged earlier than their gnathostome orthologs or that paralogs were lost, as seen by Sox 14 and Sox $5 a$ or 6 . SoxF is very similar to all variants of SoxF in jawed vertebrates, suggesting it may be an ancestral gene that was independently duplicated by jawed vertebrates.

Our expression data further support the idea that lamprey genes underwent independent gene duplications, separate from the two rounds of genome-wide duplication observed in other vertebrates. For example, in those Sox families in which we identified multiple members, we find that the lamprey genes often have overlapping expression patterns, the sum of which reflects the overall expression pattern of that Sox family in other vertebrates. Generally, each family has a high degree of overlapping expression. However, no unique ortholog was found with a pattern that is similar only to a single gnathostome Sox gene, except when we found only a single member of that family in lamprey. Sequencing of additional cyclostome genomes will provide clarity as to when such independent duplications may have occurred.

\section{Materials and Methods}

\section{Heterospecific screening of an arrayed lamprey embryonic cDNA library}

A high quality directional full-length arrayed cDNA library (SaukaSpengler et al., 2007) from embryonic day 2-12 lamprey embryos (an average efficiency of $\sim 0.9 \times 10^{8}$ transformants/ $\mu$ g of cDNA) was used for low-stringency screening. Nine individual nitrocellulose filters were screened using Sox heterospecific probes, yielding 7 different Sox genes (SoxB, E, and $F$ family members), whose identity was confirmed by sequencing on both strands, BLAST searching and phylogenetic analysis (see below).

\section{RNA-ligated mediated 5' Rapid Amplification of CDNA ends (RLM-5' RACE)}

A SoxD homologue was identified by bioinformatic survey of the lamprey genomic sequences and cloned using RACE. RACE was also used to obtain full-length sequences of the Sox genes, where cDNA clones were incomplete. Total RNA was extracted from $6,8,10$, and 14 day old embryos from Ambion:RNAquous kit. RLM-5' RACE was conducted on the total mRNA in accordance with Invitrogen: GeneRacer Kit. Total RNA was dephosphorylated through Calf Intestinal Phosphatase (CIP) treatment, decapped via Tobacco Acid Pyrophosphatase (TAP), ligated with the GeneRacer RNA oligo, and finally reverse transcribed using random hexamer priming to form the cDNA template. Gene specific primers were:

GeneRacer 5' Primer CGACTGGAGCACGAGGACACTGA

SoxB1-B: 5' CGACTGGAGCACGAGGACACTGA 3'

SoxD: 5' CGCCTCTCGTCCTTTGCCCAGAC3'

\section{Touch Down PCR}

The touchdown PCR procedure was based on the Invitrogen GeneRacer Kit. Samples were prepared in $5 \%$ DMSO, using TAQ polymerase with Roche Expand Long Template PCR Buffer 1(10x concentrated, $17.5 \mathrm{mM}$ $\mathrm{MgCl}_{2}$ ). A hot start at $94^{\circ} \mathrm{C}$ was conducted followed by 5 cycles of $94^{\circ} \mathrm{C}$ for 30 seconds and $72^{\circ} \mathrm{C}$ for 3 minutes. Another cycle of $94^{\circ} \mathrm{C}$ for 30 seconds and $70^{\circ} \mathrm{C}$ for 3 minutes was done proceeded by $94^{\circ} \mathrm{C}$ for 30 seconds, $68^{\circ} \mathrm{C}$ for 30 seconds and $72^{\circ} \mathrm{C}$ for 3 minutes for 36 cycles and a final extension at $72^{\circ} \mathrm{C}$ for 10 minutes.

\section{Cloning of the PCR product}

Extraction of the PCR product was performed corresponding to Qiagen:QIAquick Gel Extraction Kit and cloned with Invitrogen: TOPO TA Cloning. The clones were selected against the metabolism of X-gal and the production of $\beta$-galactosidase purified following the QIAprep spin miniprep kit and sent for sequencing. (Davis Sequencing, Davis, CA)

\section{Embryo collection and maintenance}

Mature or maturing Petromyzon marinus adults were obtained from Hammond Bay Biological Station, Millersburg, MI, USA. Mature animals were maintained in our lamprey facility in $12^{\circ} \mathrm{C}$ chilled re-circulating water and used for spawning. Juveniles were kept at lower temperatures before the onset of maturation and then progressively induced to maturation, by gradually augmenting the water temperature and expanding the daylight cycle. For in vitro fertilization, eggs are stripped manually from a single gravid female into a $500 \mathrm{ml}$ crystallizing dish containing $100-200 \mathrm{ml}$ of spring water and milt from a spermiated male is then expressed directly onto the eggs. After 15 minutes, the fertilized eggs are washed through several changes of distilled $18^{\circ} \mathrm{C}$ water and placed in a 4-liter container, in spring water in the 18u61904C incubator. After the first division the embryos are transferred to $0.1 \mathrm{X}$ MMR (Marc's Modified Ringers) for long-term culture. The medium from each culture is replaced with fresh one every day to avoid fungal infection. Embryos were fixed in MEMFA (4\% formaldehyde, $0.1 \mathrm{M}$ MOPS (pH 7.4), $1 \mathrm{mM} \mathrm{MgSO}, 2$ mM EGTA), dehydrated gradually and stored in 100\% methanol at -20u61904C (Sauka-Spengler et al., 2007). 


\section{In situ hybridization and histology}

Whole-mount in situ hybridization of lamprey embryos was performed using digoxigenin- or RNA probes according to Xu and Wilkinson (Xu et al., 1998), with following modifications: Prior to Proteinase K step, embryos equilibrated in the bleaching solution ( $0.5 \mathrm{XSSC}, 5 \%$ formamide, $10 \% \mathrm{H}_{2} \mathrm{O}_{2}$ ), were exposed to direct light using light box for 10-15 minutes. The concentration and the length of Proteinase $\mathrm{K}$ treatment $(\sim 20 \mu \mathrm{g} / \mathrm{ml}, 10$ minutes) was the same for embryos of all stages. Hybridization and subsequent washes were carried out at $70^{\circ} \mathrm{C}$ in hybridization solution containing $50 \%$ formamide; 1.3X SSC; 5mM EDTA pH8.0; $200 \mu \mathrm{g} / \mathrm{ml}$ yeast tRNA; 100 $\mu \mathrm{g} /$ $\mathrm{ml}$ heparin; $0.2 \%$ Tween-20 and $0.5 \%$ Chaps. The hybridization signal was detected using BM Purple substrate (Roche, Indianapolis, IN) for early stage embryos (E3-E10) or NBT/BCIP (Roche, Indianapolis, IN) for later stages. After photographing, embryos were post-fixed in $4 \%$ Paraformaldehyde/ PBS, rinsed in PBS, cryo-protected in two subsequent steps: $15 \%$ sucrose/ PBS and $7.5 \%$ gelatin $/ 15 \%$ sucrose/PBS, equilibrated and mounted in $20 \%$ gelatin/PBS and frozen in liquid nitrogen. 10 $\mu \mathrm{m}$ cryosections were collected on Super Frost Plus slides (Fischer Scientific, Pittsburgh, PA).

\section{Phylogenetic analysis}

The amino acid alignments and Neighbor Joining $(\mathrm{NJ})$ tree were constructed using ClustalX. The Maximum Pasimony likelihood tree was build using Mega. The trees were visualized using Tree View v. 0.5.0. Protein sequences from the HMG boxes of Sox family genes were used to build the alignments. Sequences form other species were retrieved from GenBank, and carry the following nomenclature abbreviations: Dr, Danio rerio; Gg, Gallus gallus; Mm, Mus musculus; Pm, Petromyzon marinus; $X I$, Xenopus laevis.

\section{Acknowledgement}

We thank Natalya Nikitina for her contribution of previously sequenced genes. This work was supported by NIH grant DE017911 to MEB.

\section{References}

BETANCUR P, BRONNER-FRASER M, SAUKA-SPENGLER T (2010). Genomic code for Sox10 activation reveals a key regulatory enhancer for cranial neural crest. Proc. Natl. Acad. Sci. USA 107: 3570-3575.

BOWLES J, SCHEPERS G, KOOPMAN P (2000). Phylogeny of the SOX family of developmental transcription factors based on sequence and structural indicators. Dev. Biol. 227: 239-255.

CUNNINGHAM DD, MENG Z, FRITZSCH B, CASEY ES (2008). Cloning and developmental expression of the soxB2 genes, sox14 and sox21, during Xenopus laevis embryogenesis Int J Dev Biol 2008;52: 999-1004.

DEHAL P, \& BOORE JL (2005). Two rounds of whole genome duplication in the ancestral vertebrate. PLoS Biology 3: e314.

ESCRIVA H, MANZON L, YOUSON J, LAUDET V (2002). Analysis of lamprey and hagfish genes reveals a complex history of gene duplications during early vertebrate evolution. Molec. Biol. Evol. 19: 1440-1450.

HONG CS, SAINT-JEANNET JP (2005). Sox proteins and neural crest development. Sem. Cell Dev. Biol. 16: 694-703.

JAGER M, QUEINNEC E., HOULISTON E, MANUEL M (2006). Expansion of the SOX gene family predated the emergence of the Bilateria. Mol. Phylogenet. Evol. 39: 468-477.

JAVERZAT S, FRANCO M, HERBERT J, PLATONOVA N, PEILLE AL, PANTESCO V, DE VOS J, ASSOU S, BICKNELL R, BIKFALVI A, HAGEDORN M (2009). Correlating global gene regulation to angiogenesis in the developing chick extraembryonic vascular system. PLoS One. Nov 17;4(11):e7856.

KISHI M, MIZUSEKI K, SASAI N, YAMAZAKI H, SHIOTA K, NAKANISHI S, SASA $Y$ (2000). Requirement of Sox2-mediated signaling for differentiation of early Xenopus neuroectoderm. Development;127:791-800

KUDOH T, TSANG M, HUKRIEDE NA, CHEN X, DEDEKIAN M, CLARKE, CJ, KIANG A, SCHULTZ S, EPSTEIN JA, TOYAMA R, DAWID IB (2001). A gene expression screen in zebrafish embryogenesis. ZFIN Direct Data Submission (http://zfin.org).
KYUNO J, MASSÉ K, JONES EA (2008). A functional screen for genes involved in Xenopus pronephros development. Mech Dev 125: 571-586.

LAUDET V, STEHELIN D, CLEVERS H (1993). Ancestry and diversity of the HMG box superfamily. Nucleic Acids Res. 21: 2493-2501.

LEFEBVRE V, LIP, DE CROMBRUGGHE B (1998). Anew long form of Sox5 (L-Sox5), Sox6 and Sox9 are coexpressed in chondrogenesis and cooperatively activate the type II collagen gene. EMBO J 17: 5718 - 5733

MARTIN BL, HARLAND RM (2001). Hypaxial muscle migration during primary myogenesis in Xenopus laevis. Dev Biol 239: 270-80

MCCAULEY DW, BRONNER-FRASER M (2006). Importance of SoxE in neural crest development and the evolution of the pharynx. Nature 441: 750-752.

MCKIMMIE C, WOERFEL G, RUSSELL S (2005). Conserved genomic organisation of Group B Sox genes in insects. BMC genetics 6: 26.

MORALESAV, PEREZ-ALCALAS, BARBAS JA (2007). Dynamic Sox5 protein expression during cranial ganglia development. Dev. Dyn. 236: 2702-2707.

NEIDERT AH, VIRUPANNAVAR V, HOOKER GW, LANGELAND JA (2001). Lamprey Dlx genes and early vertebrate evolution. Proc. Natl. Acad. Sci. USA 98: 1665-1670.

PENDEVILLE H, WINANDY M, MANFROID I, NIVELLES O, MOTTE P, PASQUE V, PEERS B, STRUMAN I, MARTIAL JA, VOZ ML (2008). Zebrafish Sox7 and Sox18 function together to control arterial-venous identity. Dev Biol 317:405-16.

PEREZ-ALCALA S, NIETO MA, BARBAS JA (2004). LSox5 regulates RhoB expression in the neural tube and promotes generation of the neural crest. Development 131: 4455-4465

PFISTER S, JONES VJ, POWER M, TRUISI GL, KHOO PL, STEINER KA, KANAIAZUMA M, KANAI Y, TAM PP, LOEBEL DA (2011). Sox17-dependent gene expression and early heart and gut development in Sox17-deficient mouse embryos. Int J Dev Biol 55: 45-58.

PRIOR HM, WALTER MA (1996). SOX genes: architects of development. Molec. Med. 2: 405-412.

RAUCH GJ, LYONS DA, MIDDENDORF I, FRIEDLANDER B, ARANA N, REYES T, AND TALBOT, WS (2003). Submission and Curation of Gene Expression Data. ZFIN Direct Data Submission (http://zfin.org)

REX M, ORME A, UWANOGHO D, TOINTON K, WIGMORE PM, SHARPE PT, SCOTTING PJ (1997). Dynamic expression of chicken Sox2 and Sox3 genes in ectoderm induced to form neural tissue. Dev Dyn 209: 323-332.

ROGERS CD, HARAFUJI N, ARCHER T, CUNNINGHAM DD, CASEY ES (2009). Xenopus Sox3 activates sox2 and geminin and indirectly represses Xvent2 expression to induce neural progenitor formation at the expense of non-neural ectodermal derivatives. Mech Dev 126: 42-55.

SAUKA-SPENGLER T, MEULEMANS D, JONES M, BRONNER-FRASER M (2007) Ancient evolutionary origin of the neural crest gene regulatory network. Dev. Cell 13: 405-420.

SAUKA-SPENGLER T, BRONNER-FRASER M (2008). A gene regulatory network orchestrates neural crest formation. Nature Rev. Molec. Cell Biol. 9: 557-568.

SCHEPERS GE, TEASDALE RD, KOOPMAN P (2002). Twenty pairs of sox: extent, homology, and nomenclature of the mouse and human sox transcription factor gene families. Dev. Cell 3: 167-170.

SMITS P, LEFEBVRE V (2003). Sox5 and Sox6 are required for notochord extracellular matrix sheath formation, notochord cell survival and development of the nucleus pulposus of intervertebral discs. Development.130: 1135-1148.

THISSE B, PFLUMIO S, FÜRTHAUERM, LOPPINB, HEYER V, DEGRAVEA, WOEHL R, LUX A, STEFFAN T, CHARBONNIER XQ, THISSE C (2001). Expression of the zebrafish genome during embryogenesis (NIH R01 RR15402). ZFIN Direct Data Submission (http://zfin.org).

THISSE B, THISSE C (2004). Fast Release Clones: A High Throughput Expression Analysis. ZFIN Direct Data Submission (http://zfin.org).

TOMSA JM, LANGELAND JA (1999). Otx expression during lamprey embryogenesis provides insights into the evolution of the vertebrate head and jaw. Dev. Biol. 207: 26-37.

VON HOFSTEN J, ELWORTHY S, GILCHRIST MJ, SMITH JC, WARDLE FC, INGHAM PW (2008). Prdm1- and Sox6-mediated transcriptional repression specifies muscle fibre type in the zebrafish embryo. EMBO Rep 9: 683-689.

WAKAMATSU Y, ENDO Y, OSUMI N, WESTON JA (2004). Multiple roles of Sox2, an HMG-box transcription factor in avian neural crest development. Dev. Dyn. 229: 74-86. 
WANG X, ONO Y, TAN SC, CHAI RJ, PARKIN C, INGHAM PW (2011). Prdm1a and miR-499 act sequentially to restrict Sox6 activity to the fast-twitch muscle lineage in the zebrafish embryo. Development 138: 4399-4404.

WOOD HB, EPISKOPOU V (1999). Comparative expression of the mouse Sox1, Sox2 and Sox3 genes from pre-gastrulation to early somite stages. Gene Exp. Pattern. 86: 197-201.

WRIGHT EM, SNOPEK B, KOOPMAN P (1993). Seven new members of the Sox gene family expressed during mouse development. Nucleic Acids Res. 21: 744.
XU Q, WILKINSON DG (1998). In situ hybridisation of mRNA with hapten labelled probes. In: Wilkinson DG, editor. In situ Hybridisation: A Practical Approach. Oxford: Oxford Press.

ZHANG C, BASTA T, KLYMKOWSKY MW (2005). SOX7 and SOX18 are essential for cardiogenesis in Xenopus. Dev Dyn 234: 878-891.

ZHONG L, WANG D, GAN X, YANGM T, HEM S (2011). Parallel expansions of Sox transcription factor group $B$ predating the diversifications of the arthropods and jawed vertebrates. PloS one 6: e16570.

\section{Further Related Reading, published previously in the Int. J. Dev. Biol.}

Sox17-dependent gene expression and early heart and gut development in Sox17-deficient mouse embryos Sabine Pfister, Vanessa J. Jones, Melinda Power, Germaine L. Truisi, Poh-Lynn Khoo, Kirsten A. Steiner, Masami Kanai-Azuma, Yoshiakira Kanai, Patrick P. L. Tam and David A. F. Loebel Int. J. Dev. Biol. (2011) 55: 45-58

A Sox 5 gene is expressed in the myogenic lineage during trout embryonic development Pierre-Yves Rescan and Cecile Ralliere Int. J. Dev. Biol. (2010) 54: 913-918

Cloning and developmental expression of the soxB2 genes, sox14 and sox21, during Xenopus laevis embryogenesis

Doreen D. Cunningham, Zhuo Meng, Bernd Fritzsch and Elena Silva Casey

Int. J. Dev. Biol. (2008) 52: 999-1004

Loss of Sox9 function results in defective chondrocyte differentiation of mouse embryonic stem cells in vitro

Gunnar Hargus, Ralf Kist, Jan Kramer, Daniela Gerstel, Angela Neitz, Gerd Scherer and Jürgen Rohwedel

Int. J. Dev. Biol. (2008) 52: 323-332

Roles of Sox factors in neural determination: conserved signaling in evolution? Y Sasai

Int. J. Dev. Biol. (2001) 45: 321-326

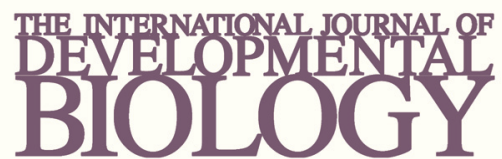

Volume 54 Nos. 6/7
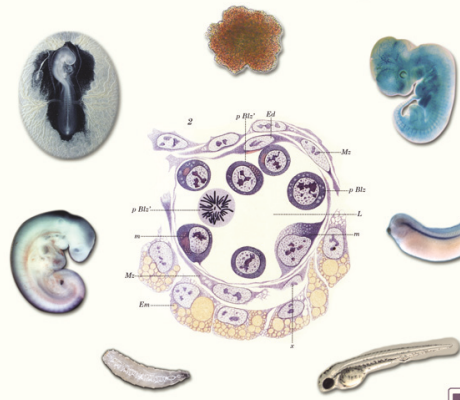

Developmental Hematopoiesis
5 yr ISI Impact Factor $(2010)=2.961$

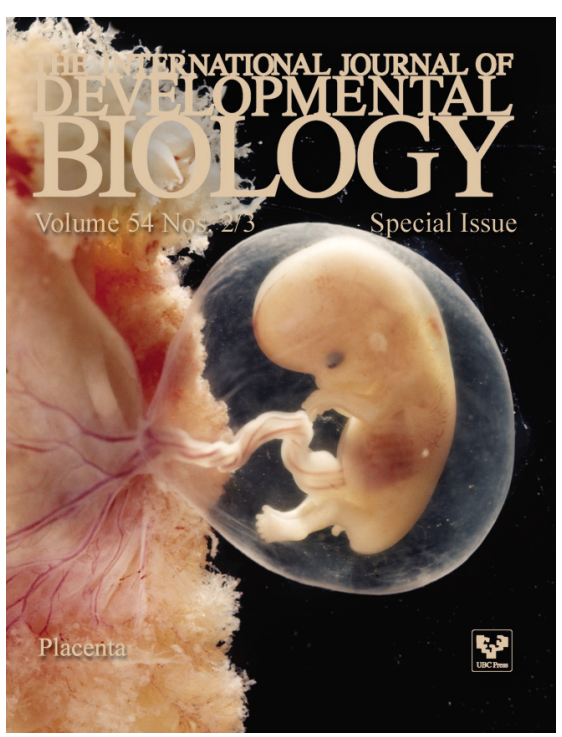

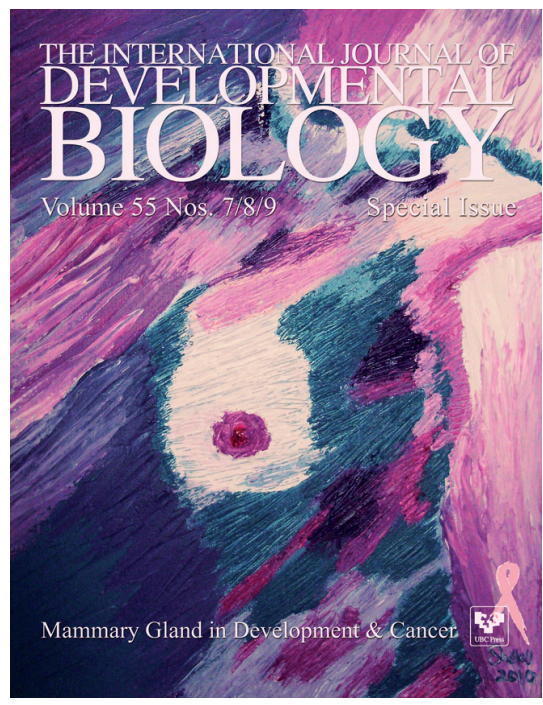

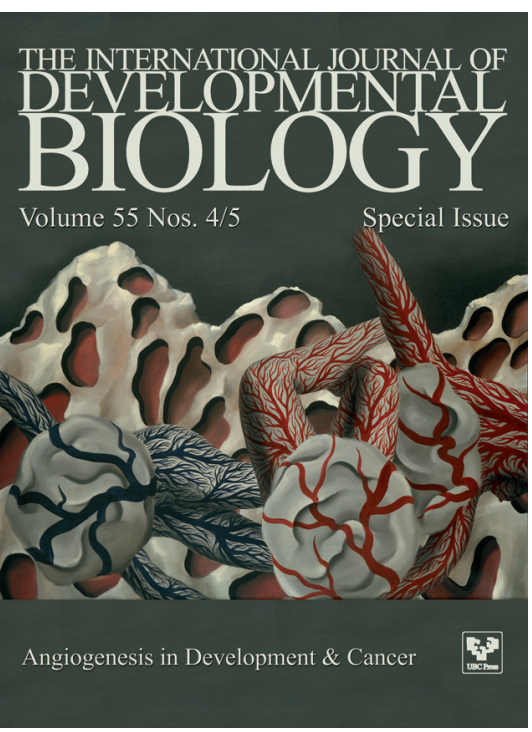

